\title{
Música, experiência e memória: o desenvolvimento da partitura e as margens do processo
}

\author{
Gabriel. S. S. Lima Rezende: \\ Doutorando em Musicologia pela Universidad de Granada (Espanha) \\ e mestrando em Sociologia pelo IFCH-Unicamp
}

\section{RESUMO}

Este texto se divide em très partes.

E.m um primeiro momento, apresenta uma leitura do processo de desenvolvimento da notação musical ocidental a partir das obras de Max Weber e Walter Benjamin.

Em seguida, discute a relação do inicio desse processo com o desaparecimento da tradiçao litúrgica hispanica e, num salto ao presente, tece uma crítica a determinados tipos de política de conservaçào das tradiçōes.

Palavras-chave: Memória. Tradição. Música

\section{ABstraCt}

This text is divided in three parts. At first, it presents an interpretation of the process of development of the Western musical notation from the perspective of the works of Max Weber and Walter Benjamin. In following, discusses the relationship between the begining of this process and the disappearance of the hispanic liturgy tradition and, in a leap to the present, makes a criticism to certain kinds of policies directed to the preservation of the traditions.

Key words: Memory. Tradition. Music 


\section{1 - Este trabalho é resultado da reefaboraçāo e ampliaça do uma comunicaçầo intitulada Musica experiencia e memónia: algumas consideraçōes sobre 0 desenvolvimento da partitura a partir das obras de Max Wober e Waiter Benjamin" publicada em junho de 2008 na Revista Espaço Acadêmico.}

2- Os gregas já haviam estabelecido toda a estrutura físicomatematica empregada até então no processo de racionalizaçāo da música. Mas para que nossa musica chegasse a se deservolver plenamente, faltava a experimentaça racional, fruto do Renascimento, a partir da qual foram estabelecidos. scculos mais tarde, os principios tećricos do temperamento $e$ sua realização prática e efotiva no piano.

3-CI. LANG P. H. "The Enlightenment and Music". In: Eighteenth-Century Studies. Baltimore: The Johns Hopkins University Press, 1967.
"Nunca houve um monumento da cultura que nāo fosse também um monumento da barbárie"

(Walter Benjamin) cultura musical ocidental se difcrencia das demais, entre outros fa-
tores, porque o desenvolvimento de nossa música esta marcado por jugo da Igreja, os mais distintos parămetros sonoros e as mais diversas práticas musicais foram sistematicamente organizados e regulamentados desde o século XII. Este primeiro impulso à racionalizacio do material sonoto-musical foi seguido por uma etapa de 'modernização secular' da vida musical, impulsionada, a partir do Renascimento, pelas atividades especulativas e práticas dos 'reformadores' da música. [2] Alguns séculos mais tarde, os intelectuais ilustrados assumiram o ideal renascentista de que a muisica deveria ser 'elevada' ao nivel de uma ciéncia, e obraram intensamente em direçào à racionalização da pratica musical até o ponto $\mathrm{cm}$ que se poderia compor a partir de um dicionario de figuras musicais. [3]

Entre os filhos pródigos desse processo está a nossa notação musical, que representa um fenomeno singular dentro da história da música dos mais distintos povos, Essa notaçio foi verdadeiramente revolucionária, pois, entre outras coisas, possibilitou a consolidaça de uma musica baseada em progressōes de acordes, a formação das grandes orquestras, a duraçào c repercussão de nosso 'patrimònio' musical e o surgimento da figura do compositor moderno. Ao mesmo tempo, essas conquistas tambèm saio manifestaçoes de um processo latente de transformacòes sociais que mostrara todo o seu vigor a partir do século XIX.

O estudo do desenvolvimento da partituma nos servira de ponto de partida para algumas reflexöes sobre a nossa 'falta de memória'. Tais reflexòes devem ser entendidas como o diagnóstico de uma tendência e rão o de uma realidade consumada.

A codificaçio da experiência musical foi uma necessidade comum a muitos povos em distintas ćpocas. Seja como um reforço para a memoria ou 
como uma forma de comunicação, a notaçio sempre foi um importante meio de transmissão dos conhecimentos musicais. O surgimento da notaçăo musjcal escrita pressupōe a existéncia de uma classe social letrada, que utiliza letras do alfabeto, silabas, palavras, números, signos gráficos, entre outros recursos, para construir um sistema de representaçào da experiência musical. Desde os babilónios podemos encontrar vestígios tanto de sistemas de notação pictográficos quanto fonéticos, destinados especialmente a descrever o processo de afinação dos instrumentos e a indicar as formas de acompanhamento do canto.

Até o século XI os instrumentistas europeus não dispunham de uma escrita, pois ao contrário do que se observa como 'regra geral', a notação musical ocidental foi desenvolvida primeiramente para o canto. A prática do cantochão, [4] foi codificada através dos neumas, signos gráficos utilizados para representar melodias que relacionavam canto e texto. Esse tipo de notacào visava basicamente a lembrar o leitor de caracteristicas fundamentais de uma melodia que já havia sido aprendida, e nāo determinar de forma exata a altura dos sons.

As açòes que influenciaram profundamente o curso do desenvolvimento de nossa escrita musical foram sistematizadas por Guido D'A rezzo, que, em 1030, propos e implementou uma reforma na notaçào musical do Ocidente. Baseado no uso de uma pauta, seu sistema
"[...] mudou completamente o relacionamento entre escrita e música em grande parte da Europa em um periodo extraordinariamente curto, e criou as pré- condicōes para desenvolvimentos de grande impor- tảncia na música ocidental" HILEY e SZENDREI (2001: 101).

A simplicidade e praticidade desse sistema, c sua capacidade de incorporar elementos de sistemas anteriores, são fatores fundamentais para explicar o rapido sucesso da reforma de D'Arezzo. Ao mesmo tempo, esse teórico contou com o apoio do Papa João XIX que ficou encantado com a possibilidade de que uma melodia desconhecida pudesse ser aprendida somente através da notação $\mathrm{O}$ sistema guidoniano tornou-se a notação musical oficial
4- $O$ cantochão é una forma de canto monofónica, caractoristica da Viturgia da Igreja Católica Romana. Sobre ele deu-se inicio, a partir do seculo XI, ao desenvolvimento da teoria musical especificamente ocidental. 
5 - HILEY, Davide SZENDREI, Janka. "Notation, III, 1 (v) (b): Plainchant: Pitch-specific notations, 11 th- $12^{\text {th }}$ centuries". In: SADIE, Stanley. The New Grove Dictionary of Music and Musicians. Londres: Mackillan, 200t, p. 101. de Roma justamente em um periodo em que o papel do papado e o relacionamento entre Roma e as igrejas locais se transformavam. A disseminação desse sistema 'coincidiu' com a época das cruzadas e fez parte do 'arsenal' [5] de reformas do Papa Gregorio VII destinadas a facilitar a reforma litúrgica e a preservar a unidade e a centralizaçäo dos costumes.

Dentre as diversas transformaçòes que se processaram nas formas de codificar a experiencia musical a partir da reforma guidoniana, podemos destacat o desenvolvimento da square notation, que sugere que o canto passou a ser pensado mais em termos de notas individuais do que $\mathrm{em}$ linhas melódicas. A maior visibilidade dada a cada nota $\mathrm{cm}$ particular fez com que esta divisăo em quadrados facilitasse o canto a partir de um 'codex', uma conquista que, tecnicamente, aumentava as possibilidades de que a prática musical não estivesse mais essencialmente ancorada no tesgate de uma experiència memorizada. A secularizaçăo da produção dos livros para o canto e o surgimento dos copistas profissionais foram impulsos importantes em direcão à simplificação e padronizaçào da escrita musical. Os livros de canto podiam ser encomendados a copistas profissionais nào familiarizados com as idiossincrasias das escritas musicais das diversas regiòes, e algumas ordens religiosas - como a franciscana, a dominicana e a agostiniana - tornaram obrigatória a sguare notation para os livros de canto. Esse processo também incidiu no estabelecimento de uma aparencia geral para os neumas, e, a partir do século XIII, predominou na Europa o modelo misto 'Alemanha-Messina', que colocava maior ènfase na nota individual em detrimento do contorno melódico.

Até entāo, o ritmo musical cra dado pelo ritmo das palavras. Mas a necessidade de racionalizar a duraçào dos sons foi ganhando força à medida que se tratava de codificar o canto polifónico, pois era necessário encontrar na escrita uma forma de coordenar as açòes das diversas vozes. Portanto, entre os séculos XIII c XIV, o desenvolvimento da notaçio se deu quase exclusivamente no âmbito do ritmo. Em um primeiro momento, a relaçió entre prática e teoria musical foi problematica, pois esta última buscava traduzir ou moldar uma tradiçào que the antecedia $\mathrm{cm}$, pelo menos, meio século. $\mathrm{O}$ sistema de 'ritmo modal' desenvolvido pelos tratadistas para descrever os cantos polifonicos era bastante impreciso, já que basicamente padronizava 
alguns modos rítmicos que eram mais frequentes na prática musical. Surge então outro personagem importante na história da música ocidental: Franco de Cologne. Esse teórico musical desenvolveu, em mados do século XIII, um sistema no qual os simbolos das notas eram capazes de indicar os modos rítmicos ao invés de serem determinados por eles. As relaçôes internas entre as figuras foram se tornando mais importantes do que as relaçòes entre elas e o texto ou o contexto musical. Ainda no século XIV, tratadistas posteriores a Franco de Cologne assumiram o seu legado e distinguiram visualmente quatro niveis principais de valores das notas ('longa', 'breve', 'semibreve' e 'minima"), estabelecendo relações binárias e ternárias entre elas. Mas foi somente no começo do século XVI que esses valores passaram a ser determinados com precisão pela aparència, independentemente do contexto em que eram identificados como 'breve', 'longa' etc. Fsse foi um passo decisivo em direção à simplificação e praticidade do sistema de notação mensural.

Tais elementos estabeleceram as bases para o desenvolvimento da notação musical observado a partir do Renascimento. Até então, os sistemas de notaçào medievais estavam dirigidos, sobretudo, aos cantores. Nos séculos seguintes, teoria e ensino foram paulatinamente sendo controlados por instrumentistas, "[...] e a notação de pauta utilizada para a maior parte do repertório foi influenciada pelas necessidades instrumentais, adotando muitas características que the permitiram expressar informaçòes cada vez mais complexas." (CHEW e RASTALI, 2001: 140) [6]

Durante este periodo também foram desenvolvidas várias propostas de reforma da notação musical com o objetivo de alcançar uma representação universal, as quais ilustram os desejos dos copistas pelo desenvolvimento de "uma notaçaio independente de qualquer estilo musical." (Idem, ibid.). Esses impulsos em direçào a um 'desenraizamento' completo da escrita musical eram acompanhados por açóes menos ambiciosas, mas certamente muito mais efetivas Copistas como o próprio Bach, por exemplo, preferiam escrever os ornamentos melódicos, e essa tendéncia acompanhou o declínio das ornamentaçōes improvisadas. No ámbito do ritmo, a falta de confiança nas formulas de compasso como indicadoras da pulsação levou ao emprego de termos específicos para este propósito. Mas até mesmo essas indicaçōes não foram suficientes. Em busca de maior precisão, os andamentos foram espe-
6- As conquistas no terreno da notação musical a partir do Renascimento anteciparam até mesmo o temperamento moderno, pois, nas pautas, a enharmonia ia estava representada graficamente. 
7 - Cf. BENJAMIN, Walter. $O$ narrador. Consideraçōes sobve a obra de Nikolai Leskov". Em BENJAMIN, Watter. Magia e Técnica, Arte e Politica: Ensaios Sobre Literatura e História da Cultura. São Paulo: Brasiliense, 1994. cificados em função do metrônomo e, a partir da segunda metade do século XX, passou-se a indicar a duração exata da peca em minutos e segundos.

Mesmo em povos possuidores de uma escrita musical, a tradição oral se manteve como o principal meio de transmissão desse conhecimento. Por outro lado, a tradição da música ocidental foi conservada especialmente através da notação musical moderna, que era capaz de determinar de maneira precisa os diversos elementos que se articulavam dentro de uma composicăo. Nas palavras de Max Weber:
"Uma notação desta espécie é, para a existência de uma música tal como a que possuímos, de importán- cia muito mais fundamental do que, digamos, a espe- cie de escrita fonética para a existéncia das formas artísticas lingüisticas [...] uma obra de arte musical moderna, por menos complicada que seja, nào po- deria ser produzida, nem transmitida, nem repro- duzida sem os meios de nossa notacio: sem ela uma obra musical moderna não pode em geral existir em lugar algum e de nenhuma maneira, nem mesmo como uma propriedade interna de seu criador." (WEBER, 1995: 119)

A partir dessa reflexão podemos desenvolver algumas questões. Além de constituir um dos pilares sobre o qual se apoia toda a música ocidental moderna, o nosso sistema de notação musical tambem se insere no processo de 'perda da memoria' que Walter Benjamin, em 1936, ja dava por consumado. [7]

Convivendo com os diversos sistemas de representação co codificaçăo que existiram ao longo da história, a tradiçào oral sempre se manteve como um elemento fundamental para a transmissăo do conhecimento musical. $O$ contato direto entre músicos abria um canal por onde melodias e ritmos podiam deslizar ao longo dos séculos e milénios. Através deles se contava e recontava uma história, e cada experiència única gatantia a sua continuaçăo. A tradiçio se mantinha, em última instäncia, na efemeridade de cada experiência musical singular.

Benjamin descreve a construçào das narrativas como um longo pro- 
cesso, pautado por um ritmo semelhante ao da formaçio da crosta terrestre: uma lenta superposição de camadas. Essa construçào pertence a determinadas formas de vivència em que o ritmo das transformaçöes está organicamente relacionado com o próprio ritmo da vida humana. [8] As transformaçóes no domínio da experiência musical seguiam um tempo semelhante, pois, em última instancia, dependiam tanto do contato direto entre duas ou mais pesscas, quanto da limitação fundamental que a tradição oral impunha ao volume e à complexidade do conhecimento que cra transmitido,

A apropriação racional dos mais diversos aspectos do fenomeno musical através da previsão e do cálculo possibilitou que o desenvolvimento da música ocidental se descolasse de tal ritmo. As infinitas possibilidades que se abriram ao racionalismo ocidental com o desenvolvimento da notaçao musical moderna alteraram a própria naturcza da experiência musical e romperam a simbiose entre tradiçào oral e escrita musical: nossa notação foi um impulso fundamental para libertar a motio musical das amarras da tradição oral. Em suas linhas e espaços puderam ser reunidos e sintetizados diversos principios e práticas musicais heterogèneos, como o contraponto, o cinone, a fuga, a imitação etc. Dessa maneira, foi possivel organizar e coordenar as açóes de um sem número de instrumentos, assim como determina-las de maneira precisa. E além de gatantir a precisão técnica da execução musical, essa notação também possibilitou uma virada qualitativa na práxis da música ocidental. $O$ desenvolvimento de uma música baseada fundamentalmente na progressão de acordes em centros tonais, particularidade especifica de nossa cultura musical, dependeu essencialmente dessa notação.

Graças a todos esses fatores, o ritmo das transformaçōes na vida musical se acelerou intensamente, deixando para trás a tradição, a narrativa, o narrador, a experiência, a memória... $A$ relaçào entre o ouvinte co narrador, que $\dot{e}$ "dominada pelo interesse em conservar o que foi narrado" (BENJAMIN, 1994: 210), pressupǒe que a experiẻncia transmitida pelo relato deve ser comum a ambos. A memória, que retinha e recriava as historias nascidas das experièncias comuns, aparece em Benjamin como a faculdade que possibilita ao narrador articular as histórias que constituem uma tradição. No entanto, as condiçōes sociais que permitiam uma "experiência e uma narmaividade espontineas" (GAGNEBIN, 1994: 9), estruturadas em torno
8 - Cf. BENJAMIN. Walter. Ob. cit 
9 - Por exemplo: em afgum momento, as fómulas de

compasso

mantinham rolaçāo

direta com a vida

musical, e por isso

eram capazes de indicar a pulsação a ser seguida. Se por um lado, a cantusio criada pela dificuldade de determinação da pulsaçāo atesta uma necessidade de controle cada vez mais intensa sobre a composiçāo, bem como o incremento de sua complexidade, por outro da manifesta a faita de um referencial comum que faca convergir a expectativa de sou(s) exocutante(s).

10 - E é justamente no contexto dos nacionalismos musicais que os compositores vä́o buscar nos redutos ern que se mantém vivas algumas tradiçóes os elementos para construir uma "identidade nacional.

11 - Cf. HILEY, D. e SZENDREl, $J$. Ob.cit., p. 88 . de uma organizaçăo comunitúria centrada no artesanato, foram destruidas pelo desenvolvimento do capitalismo e da tecrica. Ou seja, perdera-se a capacidade de intercambiar experièncias, pois jä nem existem experiências comuns, nem as próprias condiçōes para que elas possam ser contadas $e$ recontadas. Portanto, a destruiçio dos antigos laços comunitários e a perda da capacidade de intercambiar experièncias também anunciam o fim da memória e da tradição.

Se as transformaçóes ocorridas entre os seculos XI e XV dão inicio ao desmanche do tecido da memória musical, a partir do Renascimento já co meçamos a vislumbrar as suas consequéncias. As determinações dos diverSos àmbitos da execução musical são cada vez mais estabelecidas em funçio de uma ordem abstrata. [9] No decurso de seu desenvolvimento, a partitura passa a se alimentar das próprias relaçòes internas entre os elementos musicais. E estes últimos também vào se distanciando paulatinamente de suas origens numa tradiçáo musical concreta até o ponto em que qualquer lastro de uma realidade viva se torna desnecessirio. [10]

\section{II}

Não existe evidència concreta em parte alguma do Ocidente de que qualquer forma de notaçào musical tenha se desenvolvido antes da era Carolingia. [11] Os rituais litúrgicos, guiados fundamentalmente pelos textos das oraçoes, variavam de acordo com os costumes e as tradiçòes das regiòes em que eram praticados. Entretanto, os reis francos encontraram na liturgia um poderoso meio para a expansào política do império, e, sendo a necessidade a mảe da invenção, a possibilidade de codificaçào dos cantos tornou-se uma condiçáo técnica indispensável para o bom funcionamento dos planos imperiais. Enquanto se esforcavam para alinhar as suas práticas musicais com as da liturgia romana, o espirito expansionista de Pepino o Breve (rei entre 751 e 768) e, especialmente, o de seu sucessor, Carlos Magno (rei entre 768 e 814), tornaram extremamente fecundo o terreno da invençào. Embora as informaçoes não sejam precisas, $\dot{\mathrm{e}}$ muito provável que o contato entre as igrejas carolingias e bizantinas tenha aberto as portas do Ocidente à penetração de algumas formas de notaçäo musical, e que Carlos Magno as tenha 
incluido em seu amplo programa de reforma educacional destinado à revitalização do clero e da cultura antiga. [12]

12 - Ibid.

"Reformar a Igreja não implicava apenas revigorar os quadros de um ensino gramatical, comentar novamente os poetas latinos para que Santo Agostinho voltasse a ser inteligivel aos bispos e para que estes pudessem compor homilias à maneira de São Jerônimo e de Gregório, o Grande. Era preciso ainda que as cerimónias do culto atingissem novamente a perfeiçäo, e, para isso, que os modelos antigos voltassem. Carlos Magno impós ritos romanos e cantos gregorianos em todo o seu reino, e substituiu, na maioria dos monastérios, os costumes locais por formas de vida cenobíticas, elaboradas há pouco tempo no coraçào da Italia, prescritas pela ordem de Säo Bento." (DUBY, 1988: 133)

Ou seja, a notação musical era levada a tiracolo do poder imperial, e com ele se confundia.

Por motivos bem diferentes, o ambiente no qual se praticava a liturgia hispanica também era favorável ao desenvolvimento da notação musical. As fortes heranças romana e pré-romana presentes na peninsula, associadas à antiga cristianizaçào e ao estreito contato com a liturgia judaica, ajudaram a fixar o rito hispánico na tradiça latina, em contraposição ao arianismo dos governantes visigodos de origem germânica. Desse modo,

“[...] a transferéncia ou conversão dos signos de pontuação greco-latina em neumas era mais fácil de concretizar-se na Espanha, onde a romanizaçio foi muito profunda e onde o sermo molgaris ainda era praticado nos séculos VIII e IX por uma grande parte da populaçào". (FERNÁNDEZ DE LA CUESTA, 2004: 157)

Entretanto, as origens da notação musical hispainica também não são claras. [13] Além da expansão do império carolíngio, iniciada com Pepino o Breve, e das circunstancias anteriormente citadas, o contato com a cul-

13 - O Antifonário de León funico antifonario mozarabe conhecido), por exemplo, que foi escrito em 1069 , contém uma nota na qual se diz que fora copiado de outro livro que dataria de 672 . 
tura árabe e a distância em relação a um centro forte de controle podem ter sido fatores que estimularam o seu florescimento. Assim, essa notacäo pode desenvolver-se in campo aperio, ou seja, sem as linhas e os espaços que situavam e enquadravam de maneira mais precisa e racional as alturas das notas cantadas. $\mathrm{E}$, ainda que apresentassem as mesmas caracteristicas gerais das outras formas de notação existentes naquela época, os neumas hispaninicos possuiam particularidades que os diferenciavam de maneira clara dos demais. Essa notação foi empregada para codificar os cantos moçárabes, inicialmente criados e mantidos pela tradição oral, cuja 'frescura' e 'espontaneidade' contrastavam " $|\ldots|$ com a sobriedode da cucologia romana, cujas oraçöes, sumamente breves e concisas, est[avam] compostas segundo um padrào ou arquétipo inamovizel". (FERNÁNDEZ DE LA CUESTA, 2008: 139) [Grifo meu]

Se o dominio arabe não representou uma ameaça a sobrevivencia do rito hispanico, o mesmo näo se pode dizer a respeito do impeto expansionista de Carlos Magno. Até então, frente ao poder da igreja romana,

"O intercambio de costumes e a adoção de alguns textos não afetavam em nada a identidade, independência e a diversidade dos usos litúrgicos em seu conjunto, fielmente custodiados pelos bispos $\mathrm{em}$ cada diocese e pelos concílios nas provincias," (FERNÁNDEZ DE LA CUESTA, 2004: 218)

Mas, à exceção da Catalunha, as tentativas do imperador de submeter a igreja espanhola a lex monana enfrentaram as mais diversas formas de resistência por parte das várias regiòes peninsulares. $O$ embate mais ferrenho deu-se com um bispo "enérgico e culto, zeloso das antigas tradiçöes, Elipando de Toledo" (Idem, ibid.: 219). Como o bispo toledano se encontrava debruçado sobre os livros sagrados quando verteram sobre a sua cabeça a acusaça de heresia, esta se espalhou sobre os próprios textos da liturgia hispànica.

"A partir de então [em território peninsular], to- 
dos os tipos de ações estarão encaminhadas a suplantar a liturgia hispànica pela romano-carolíngia, sob o pretexto de ambiguidade doutrinal $\mathrm{em}$ alguns pontos", (Idem, ibid.)

e, fiel a sua antiga tradição,

"[... o resto da Peninsula sentiu que a permanência de sua prática ritual estava em perigo frente às constantes ameaças de supressão que vinham do outro lado dos Pirineus, mesmo depois de passada a crise adocionista iniciada por Elipando de Toledo". (Idem)

A implantação do canto gregoriano, afirma Fernández de la Cuesta,

"[..] colocava problemas muito sérios aos centros eclesiásticos, seculares e monásticos. $A$ celebração da liturgia ainda repousava $\mathrm{em}$ grande medida sobre uma tradição oral fortemente enraizada. Clérigos e monges sabiam de cor as fórmulas e as estruturas dos oficios, portanto é fácil imaginar $o$ esforco lào gigantesio que deveria ser realizado para mmdar a valz da tradiçäo." (Idem, ibid.: 222) [Grifo meu]

Se o problema da tradição repousa nas pessoas, nada mais racional, naquele contexto, do que repovoar as igrejas e monasterios com clérigos e monges vindos de fora, e carregando consigo numerosos códices concordantes com a nova ordem. Carlos Magno deu o impulso inicial a esse processo que, a partir do século IX, foi amplamente fortalecido com a penetração dos monges e da regra beneditina nos monastérios hispànicos, a qual alterava as formas de vida comunitárias e, sobretudo, as práticas litúrgicas, segundo os modelos do ritual gálicoromano. Dessa forma, pouco a pouco, as resisténcias foram sendo minadas e o rito romano foi gradualmente apagando os seus predecessores. Os sinais desse processo ainda estào vivos nas marcas de raspado presentes nos codices Emilianense 56 e Liber ordinssm, que substituiram 
14 - Os simbolos da notaçäo aquitana eram menos numerosos e seus traços mais simples. tornando mais pratica a vida dos cantores. Além disso, representava de maneira absoluta os intervalos pelos quais discorria a melodia. a antiga notação in compo apperto pela notaçào aquitana, notação 'oficial' do rito romano-gregoriano, desenvolvida especialmente a partir do século XI, que espreme os neumas entre linhas e espaços para deles extrair maior definição. [14]

As tensōes com Roma mantiveram um certo equilibrio até 1065 , quando um legado do papa Alejandro II visitou a Espanha com ordens concretas de suprimir o ritual autóctone. Com a ascensão do Papa Gregório V1I, que colocou-se a carefa de harmonizar a humanidade segundo a vontade divina, essa nova política expansionista conseguiu suprimir definitivamente o rito hispánico. Imediatamente após ascender ao poder em 1073, o novo papa dirigiu uma bula aos reis de Castela e Leão intimidando-os a abandonar a antiga prática hispanica em favor do novo ritual. $A$ igreja hispanica deveria estar subordinada à igreja romana que, "fundada sobre a base de Pedro e Paulo, está garantida contra toda alteração" (Idem, ibid.: 220), Enquanto insistisse em sua autonomia, a igreja hispànica seria "uma nota discordante no unissono do Ocidente e Setentriào" (Idem, ibid.). De imediato, houve uma cisão entre os reinos peninsulares que aceitaram e os que não aceitaram submeter-se definitivamente à lex mana. Quando da implantação do rito romano no monastério de Sahagun (na província de Leão), em 1079, os monges leoneses fugiram e, desse modo, conseguiram adiar momentaneamente o sufocamento de suas tradiçōes. $\mathrm{A}$ ameaça de supressão também deu impulso a uma intensa atividade de cópia de todo tipo de códices litúrgico-musicais. Fntretanto, fiéis as suas tradiçóes, os copistas mantiveram a escrita dos neumas in canpo aperto. Mesmo que a proximidade e as boas relaçòes com a Aquitảina fossem favoráveis à utilizaçào da notação desta última regiăo, tecnicamente mais avançada,

"[...] os eclesiasticos e os monges hispanticos viram na escrita [aquitana] um perigo para sua própria tradiçào e nào a aceitaram, já que o rito gálico-romano que se tentava introduzir na Peninsula vinha assim escrito. Se aferraram, pois, a [sua| escrita como ao [seu] próprio rito." (Idem, ibid.: 221-22)

Como já sabemos, o rito hispánico desapareceu no final do século XI 
e dele restaram apenas duas dezenas de cantos transcritos para a notaçào aquitana e um enorme repertório que permanece indecifrável.

Voltamos aqui ao ponto de partida deste trabalho. A supressào do rito hispanico ocorre justamente no momento das reformas paradigmáticas na notaçäo musical empreendidas por Guido D'Arrezzo, que foram incorporadas nas reformas do Papa Gregório VII, e que estabelecem um dos pilares fundamentais para o processo de racionalização da música ocidental. Não quisemos estabelecer aqui nenhuma relaçăo direta entre as reformas guidonianas e a suplantaçào do rito hispannico, apenas destacar que a implantaçăo do canto gregoriano nāo foi um fato isolado. Ela se enquadrou "[...] em um amplo marco de decisóes políticas e religiosas que representavam uma mudança qualitativa na igreja e na sociedade perante o futuro." (Idem, ibid.: 217) Interpretamos essa mudança como um pequeno sinal de fumaça, que nem imagina o incêndio que anuncia. Quando, no século $\mathrm{XV}$, Jiménez de Cisneros chegou a Toledo e se deparou com o que restava da antiga tradiçào dos cantos moçárabes, logo tratou de reformá-la e revitalizá-la. Mas Cisneros jả estava espiritualmente ligado a uma nova época, c enviou uma comissão de técnicos nomeada especialmente para organizar a tradição decadente. Esse trabalho de recuperação deu origem a quatro cantorais, que oferecem

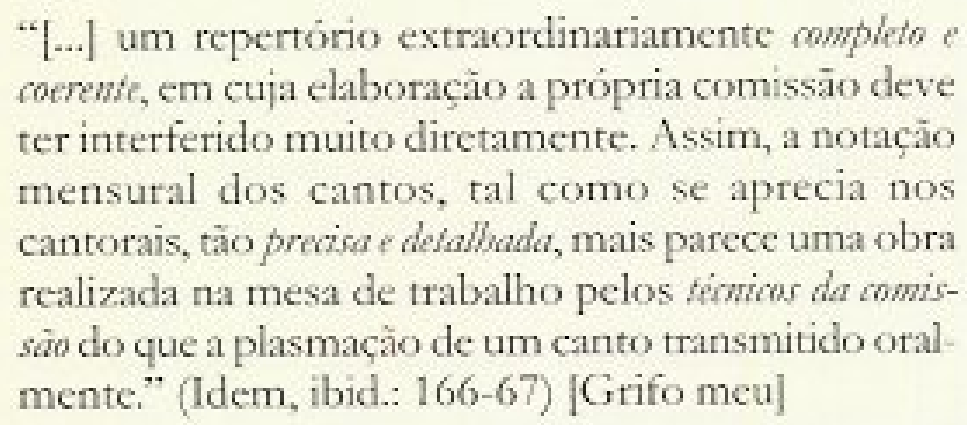

Vemos, portanto, que desde os seus primórdios, o desenvolvimento da notação musical no Ocidente também esteve vinculado ao poder e à dominaçào. Devemos congelar o momento da fuga daqueles monges leoneses, levando as suas tradiçòes embrulhadas na memória, para entendermos que o progresso esconde feiçòes monstruosas. As tradiçòes que 
$15-\mathrm{Ct}$.

GUARDIANES de un tesoro musical: el barroco boliviano. Direção: Peter Conrad. Producuio: Juan-Luis Suarez. Canadá/Bolvia, 2007 (45min).

16 - Cl. UNESCO Advisory Body Evaluation, 1990. Disponivel em: hito: Who.unesco.orgien/ list/529. Acesso em: 10 maio 2009 foram apagadas ainda resistem nas marcas raspadas de suas ausências, na imprecisão de seus símbolos, e ainda nos incomodam como um ponto cego $e$ indecifrável na Historia.

\section{III}

Entre o final do século XVII e a primeira metade do século XVIII, os jesuitas fundaram seis cidades na parte oriental da Bolivia. A regiào à qual pertenciam ficou conhecida como Chiquitos. Esta última também faz parte de um conjunto mais amplo de províncias conhecido como Chiquitania, que foi preservado após a expulsäio dos jesuitas. $A$ atividade evangelizadora ali desenvolvida tinha na música um de seus principais pilares. Os jesuitas se foram, mas, periodicamente, uma grande quantidade de partituras originalmente trazida por esses religiosos era recopiada pelos proprios indigenas, mesmo que estes já não soubessem mais como interpretar os seus simbolos e as usassem, antes de mais nada, como uma espécie de objeto ritualistico que deveria estar presente no momento da execução musical. A música $\mathrm{cm}$ si fora guardada, transformada c transmitida basicamente através da tradição oral.

Nas últimas décadas, a Chiquitania vem sendo 'redescoberta' junto com o seu instigante acervo de partituras. [15] Rapidamente, um conjunto de açōes foi posto em marcha para estudar, analisar e preservar essa 'auténtica manifestaça cultural. Um primeiro projeto para a preservacão dessa regiāo foi apresentado em 1976, com o titulo de "Las antiguas misiones jesuiticas de Moxos y Chiquitos. Posibilidades de su aprovechamiento turistico". Em 1990, seis igrejas das missỏes jesuítas de Chiquitos receberam da Unesco o selo de "Patrimônio Mundial da Humanidade". [16] Mas as iniciativas não pararam por ai. Vendo que a memória dos indigenas nào fora capaz de preservar a herança barroca com a sofisticaçào musical que ela 'merece', especialistas foram enviados a regiào para ensinar aos chiquitanos a 'melhor forma' de preservar suas proprias tradiçòes. Professores de música vindos do velho continente ensinaram as mais sofisticadas técnicas de execuçŏo dos instrumentos e as formas corretas de interpretar as partituras que ali repousaram durante séculos; Juthers também curopeus levaram o que há de melhor nas técnicas de construçảo para melhorar a qualidade dos instrumentos produzidos pelos artesãos chiquitanos. Entre os produtos desse novo espirito está o 
Festival de Música Renacentista y Barroca Americana "Misiones de Chiquitos", que em 2008 chegou a sua sétima edição. Enquanto os jovens encontram na música uma 'oportunidade de crescer na vida e ocupar produtivamente o tempo que passavam à toa', a antiga e desgastada tradiçāo, que sobrevivia na memória dos 'viejos chiquitanos', anuncia o seu desaparecimento.

Vemos, portanto, que a dominação hoje tem uma cara muito mais sedutora. Quando a notação musical jả se encontra há muito tempo superada pelas técnicas modernas de produçio e reprodução, o discurso pós-moderno exalta a inclusão democrática de todas as manifestações culturais dentro da ordem vigente, e deixa seus apologistas de boca cheia para falar de suas contribuiçōes para o desenvolvimento da cultura mundial.

Na parte que nos toca, falemos do bem que fazemos para a divulgação das 'verdadeiras culturas étnicas'. Não estaremos nós também reivindicando os restos decompostos de antigas tradiçòes e, maldosamente, os transformando em porta-vozes do todo harmonioso? Para aqueles lugares reconditos onde a tradição agoniza, não mais se dirigem os monges letrados nos ritos oficiais do Império, mas sim nossos técnicos especialistas arregimentados pelo mercado junto as universidades, ministérios e outros centros do poder moderno (ou pós-moderno, como queiram) e apoiados nos programas de incentivo cultural, política de patrimônio imaterial e leis de 'inclusào social" - para tudo incorporar no espetáculo da democtacia cultutal. Ragas indianos, bulerias ciganas, rituais xavantes... Façamos cds, dvds, shows, artigos, livros. O público chora de emoção, mas em suas lágrimas se reflete a imagem distorcida das tradiçōes que agonizam.

\section{BIBLIOGRAFLA}

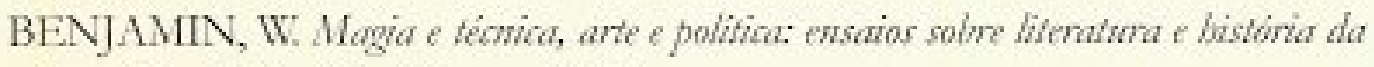
callura. Sào Paulo: Brasiliense, 1994.

BENT, I. D./ HUGHES, D. W., PROVINE, R. C., RASTAL., R. (I-II, com KILMER, A., 1, 2), HILEY, D., SZENDREI, J. (III, 1), HILEY, D./PAYNE, T. B. (III, 2), BENT, M. (III, 3), CHEW, G./RASTALL, R. (III, 4-6). Verbete "Notation". In: SADIE, S. The New Grove Dictionary of Music and Musicians. Londres: MacMillan, 2001.

FERNANDEZ DE LA CUESTA, Ismacl. "Liturgia e improvisación". In: 
"La voz y la improvisación". Simposio Sobre Patrimonio Inmaterial, 2007, Urueña, Valladolid: Fundación Joaquin Diaz, 2008.

- Historia de la Música Española. 1. Desde las Origenes Hasta el "Ars Nona". Madri: Alianza, 2004.

GAGNEBIN, J. M. "Walter Benjamin ou a historia aberta". Prefácio a BENJAMIN, W. Magia e Técnica, Ante Politica: Ensaios Sobre Literatura e Históna da Guitura. São Paulo: Brasiliense, 1994.

LANG, P. H. "The Enlightenment and Music". In: Eighteenth-Centroy StudiesBaltimore: The Johns Hopkins University Press, 1967.

LIMA REZENDE, Gabriel S. S. "Música, experiència e memoria: algumas consideraçòcs sobre o desenvolvimento da partitura a partir das obras de Max Weber e Walter Benjamin". In: Retista Espaco Academico. N.o 85 - Jun. 2008. Disponivel em: wwwespacoacademico.com.br/085/85rezende.htm WEBER, M. Os Fundannentos Racionais e Sacioliggios da Música. Sào Paulo: Edusp, 1995.

UNESCO. Advisory Body Evaluation, 1990. Disponível em: http:// whc.unesco.org/en/list/529. Acesso em: 10 maio 2009.

GLARDLANES de an tesoro musical el barraco boliwano. Direçio: Peter Conrad. Produçio: Juan-Luis Suárez. Canadá/Bolivia, 2007 (45min). 